\title{
Direito à educação: a matrícula da pessoa com deficiência intelectual na rede regular de ensino
}

Right to education: the school enrollment of people with intellectual disabilities

\author{
Luiz Alberto David Araujo \\ Maurício Maia
}

\begin{abstract}
RESUMO
0 direito à inclusão e à educação das pessoas com deficiência são garantidos pela Constituição, que tem na igualdade um de seus principais valores. Partindo de notícia publicada na imprensa, que denuncia a dificuldade das pessoas com deficiência de efetivarem sua matrícula escolar na rede regular de ensino, este trabalho analisa a atual configuração constitucional dos direitos à inclusão e à educação daquele grupo vulnerável, apontando os caminhos oferecidos pelo ordenamento jurídico brasileiro para a garantia e para a efetivação desses direitos. Todos os danos causados pela recusa da matrícula, difusos ou individuais, morais ou materiais, são passíveis de reparação.
\end{abstract}

Palavras-Chave: Atendimento educacional especializado. Educação. Pessoas com deficiência.

\begin{abstract}
The right of inclusion and education of people with disabilities are guaranteed by the Brazilian Constitution, that has in equality one of its core values. From a newspaper report, denouncing the difficulty of people with disabilities to actualize their enrollment in the regular school system, this article analyzes the current constitutional configuration of rights to inclusion and education of that vulnerable group, pointing out the ways offered by the Brazilian legal system to guarantee and actualize these rights. Any damage caused by the refusal of the school enrollment, diffuse or individual, moral or material, are liable to repairing.
\end{abstract}

Keywords: Specialized educational services. Education. People with disabilities. 


\section{Introdução}

O presente artigo parte de uma notícia veiculada em jornal diário de grande circulação. Não é notícia nova, no entanto. Trata-se de tema recorrente, qual seja, a dificuldade de se conseguir vagas em escolas para pessoas com síndrome de Down. No caso, uma jornalista se passa por mãe de uma criança. Os argumentos para justificar a impossibilidade de ingresso de boa parte das escolas são os mesmos. A partir daí, o artigo propõe uma análise sobre o direito à educação, sobre o direito à educação inclusiva e sobre as consequências que podem advir da negativa das escolas, procurando mostrar que o tema pode ser judicializado, oferecendo caminhos para tanto. Da tutela individual para a coletiva, o trabalho expõe as alternativas, procurando tornar o direito à inclusão das pessoas com deficiência algo mais efetivo.

Aproximadamente um quarto da população brasileira apresenta alguma deficiência ${ }^{1}$. Atualmente no Brasil, mais de 45 milhões de pessoas alegam ter alguma deficiência, o que nos dá a dimensão do tamanho desse grupo de pessoas.

Tratar dos direitos desse grupo vulnerável é discutir tema relevante e necessário para o bom entendimento da efetividade constitucional.

É isso o que pretende o artigo: analisar o conteúdo do direito material à educação inclusiva e, diante da falta de efetividade, apontar os caminhos para a sua realização.

O artigo estrutura-se partindo da análise da Constituição Federal, especificamente do direito à inclusão que dela exsurge, assim como da configuração que a Lei Maior dá ao direito à educação. Na sequência, abordaremos o direito à educação sob o enfoque das pessoas com deficiência, analisando a legislação acerca do tema. Após, passamos a verificar os danos causados pela recusa da matrícula da pessoa com deficiência na rede regular de ensino, chegando, finalmente, aos mecanismos presentes em nosso ordenamento jurídico para a efetivação do direito à educação das pessoas com deficiência. 


\section{A Constituição Federal e o direito à inclusão social}

Um dos objetivos fundamentais da República Federativa do Brasil é a construção de uma sociedade livre, justa e solidária (Constituição Federal, artigo 3ํㅡ, I), sendo também um objetivo fundamental de nossa República a promoção do bem de todos, sem quaisquer formas de discriminação (Constituição Federal, artigo 3o, IV).

Não se pode pensar em uma sociedade livre, justa e solidária, tampouco na promoção do bem de todos, se não pensarmos em uma sociedade inclusiva, que acolha a todas as pessoas, reconhecendo que o ser humano apresenta grande diversidade, e que todos devem poder conviver de forma harmoniosa, com as mesmas oportunidades de desenvolverem plenamente suas potencialidades. Ademais, a igualdade, pressuposto da inclusão, é um valor extremamente caro ao nosso Texto Constitucional, garantido como direito fundamental no artigo $5^{\circ}$, caput e inciso I. Não é por menos que o Brasil é signatário da Convenção Sobre os Direitos das Pessoas com Deficiência da ONU, que foi recebida em nosso ordenamento jurídico com status de emenda à Constituição, na forma do art. 5ํㅡ, §3ํㅡㄹ da Lei Maior, ou seja, o Decreto Legislativo no 186, de 09 de julho de 2008, que a internalizou, foi aprovado em dois turnos, por dois terços dos membros de cada uma das Casas do Congresso Nacional. 0 Poder Executivo promulgou a Convenção mediante o Decreto no 6.949, de 25 de agosto de 2009.

A inclusão plena de todas as pessoas não é algo que se consiga apenas com determinações legislativas, mas são necessárias ações, muitas vezes de longo prazo, que, estimulando a convivência, façam incutir na consciência da coletividade que todos somos de fato iguais, apesar de nossas peculiaridades. A segregação de um grupo de pessoas, simplesmente pela inexistência de um ambiente que propicie seu adequado acolhimento, sempre gerará mais segregação; somente com a convivência se desenvolve a consciência de quem é o outro (ARAUJO, 2014).

Devemos notar que o ser humano começa o desenvolvimento de sua sociabilidade na sua família e, em seguida, na escola. É normalmente no ambiente escolar, na convivência com os colegas, a primeira experiência 
de convivência do ser humano com outros de sua idade. Se no ambiente escolar não se estimula a convivência com a diferença, muito mais difícil será esse processo nas etapas subsequentes da vida.

Por outro lado, poucos direitos são tão importantes como o direito à educação, que garante o acesso do ser humano ao instrumental necessário para o exercício da cidadania, para o pleno desenvolvimento pessoal e para a inclusão no mercado de trabalho; sem educação dificilmente o ser humano consegue atingir qualquer objetivo de desenvolvimento.

Somente por intermédio da educação poderá o ser humano subsistir com dignidade, com capacidade para escolher os seus caminhos sociais e pessoais. Não há liberdade sem educação. Os direitos fundamentais não serão mais do que palavras vazias de significado se não puder o ser humano adequadamente conhecê-los e estar preparado para exigir sua garantia. 0 Estado Social e Democrático de Direito não existirá se o seu povo não estiver preparado para dirigir os seus rumos, e tal preparação dá-se justamente pela garantia, e efetivação, do direito à educação.

A exclusão das pessoas com deficiência do ambiente escolar, assim, gera perdas irreparáveis tanto para as pessoas com deficiência, que têm seu direito à educação mutilado, como para as demais pessoas, que ficam privadas da convivência com a diversidade, deixando de desenvolver seus sensos de tolerância e solidariedade, empobrecendo muito sua experiência educacional. 0 direito à inclusão social é reconhecido, claro e evidente. Mas há um outro direito que surge com o convívio das pessoas com alguma diferença: o direito da maioria de poder conviver com a minoria. Convivendo em escolas comuns, pessoas com deficiência e sem deficiência estarão dividindo tarefas e atividades, envolvendo-se reciprocamente, quebrando a barreira da "diferença". Todos se respeitarão, porque conhecerão as formas de conviver, que será aprendida, em um esforço que refletirá o que de mais bonito aparece no ser humano: aprender com o outro. E assim teremos pessoas sem deficiência aprendendo a viver, a respeitar e a partilhar sua vida escolar com algum colega que apresenta alguma diferença. 0 "medo" do diferente se transforma em desafio do dia-a-dia, para acolher aquele que precisa de alguma ajuda.

É possível, porém, utilizando-se dos meios colocados à disposição pelo Direito brasileiro, garantir o acesso adequado das pessoas com 
deficiência à educação, efetivando o Texto Constitucional, como procuraremos expor neste trabalho.

\section{A Constituição Federal e o direito à educação}

A Constituição brasileira, na configuração do Estado Social e Democrático de Direito em que se constitui nossa República, garante a todos, em seu artigo 205, o direito à educação, colocando-o como um dever do Estado e da família, a ser promovido com a colaboração da sociedade, com a finalidade de desenvolver plenamente a pessoa, preparando-a para o exercício da cidadania e qualificando-a para o trabalho.

0 oferecimento do serviço público de educação será realizado diretamente pelo Estado, bem como é autorizado aos particulares, nos termos do artigo 209 da Lei Maior, que determina a observância pelos particulares que prestem tal serviço público das normas gerais da educação nacional, sendo submetidos a avaliação de qualidade pelo Poder Público. A coexistência de instituições públicas e privadas de ensino, aliás, é um dos princípios com base nos quais será ministrada a educação (artigo 206, III, in fine, da Constituição).

Destina-se a educação não apenas à instrução das pessoas, mas também à sua formação como cidadãos, ao seu pleno desenvolvimento pessoal e à inserção no mercado de trabalho.

Aqui é de se notar a clara conexão da disposição do artigo 205 da Constituição com um dos fundamentos republicanos trazidos pelo artigo

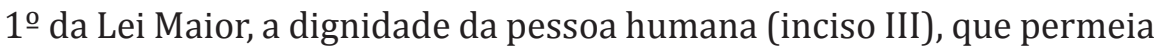
todo o Texto Constitucional.

A cidadania, o pleno desenvolvimento pessoal e a preparação para o labor são elementos indispensáveis para que o ser humano exista com dignidade, possa viver de forma harmônica, altiva e independente na sociedade.

A educação deve preparar a pessoa para a convivência plena e efetiva na sociedade, em igualdade de oportunidades para com as demais pessoas, conferindo-lhe meios para a subsistência com dignidade e autonomia. Formar cidadãos, pessoas que participem da elaboração 
da vontade soberana do Estado brasileiro, seres humanos que possam desenvolver plenamente suas competências e habilidades, obtendo com seu trabalho os meios necessários para sua subsistência e bem-estar, é a função da educação.

0 artigo 206 da Constituição da República fixa os princípios que regem o ministério da educação no Brasil, constando dentre eles, logo no inciso I do referido dispositivo constitucional, a igualdade de condições para o acesso e permanência na escola.

Nota-se logo de início a preocupação da Constituição com a igualdade, que é, se não o principal, um dos principais vetores de interpretação da Lei Maior. De fato, a Constituição Federal coloca como um dos objetivos fundamentais da República a construção de uma sociedade livre, justa e solidária (artigo 3ํㅜㄹ inciso I), garantindo o direito à igualdade já no caput do seu artigo 5ำ, fixando a cláusula genérica segundo a qual "todos são iguais perante a lei". No mesmo caput do artigo 5o da Constituição, que encima e condiciona todo o rol, não exaustivo, diga-se, de direitos e garantias fundamentais trazido na Lei Maior, novamente garante-se aos brasileiros e estrangeiros residentes no país o direito à igualdade. Como se não bastasse a garantia do direito à igualdade e a cláusula genérica da igualdade perante a lei, contidas no caput, o artigo 50 da Constituição, em seu inciso I, estabelece a cláusula de que homens e mulheres são iguais em direitos e obrigações, demonstrando a importância que o Constituinte atribuiu a tal valor. Note-se que apenas a cláusula de que "todos são iguais perante a lei" já bastaria para que todo o sistema de direitos e garantias fundamentais estabelecido na Constituição tivesse sua interpretação e aplicação condicionada pela igualdade, ou seja, já seria suficiente para garantir a igualdade de todos; o Constituinte, porém, preferiu reforçar diversas vezes essa cláusula genérica, apontando sua importância no Texto Fundamental.

No caso da educação novamente a Constituição privilegia a igualdade, determinando que todos devem ter as mesmas condições de ingressarem e permanecerem na escola; ora, essa igualdade de condições de acesso e permanência na escola já poderia ser perfeitamente extraída da cláusula de que "todos são iguais perante a lei" ou mesmo do direito à igualdade trazido pelo caput do artigo 5ํㅜ da Constituição, mas preferiu o 
Constituinte por fixar novamente a igualdade, de acesso e permanência, como um dos princípios básicos da educação no Brasil.

Dessa forma, temos que o direito de todos à educação, que deve ser garantido pelo Estado e pela família, tem como princípio o acesso e a permanência na escola de forma isonômica, por expressa disposição constitucional. A Lei Maior determina a igualdade no direito de acesso à escola, impondo, ainda, que sejam adotados todos os esforços destinados a permitir que as pessoas com deficiência possam conviver no ambiente escolar em igualdade de condições para com as demais pessoas.

Não se admite a prestação de serviço de educação pelo Estado, ou pelos particulares autorizados, se não for dentro de parâmetros que garantam a isonomia de acesso e permanência nas escolas. A educação é serviço público essencial e igualitário.

Todos, pessoas com deficiência ou sem deficiência, têm o mesmo direito à educação, sendo de rigor que haja mecanismos hábeis a promoverem a equiparação de todos.

Garante a Constituição, ainda, a liberdade de aprender, ensinar, pesquisar e divulgar o conhecimento, a arte e o saber, bem como o pluralismo de ideias e de concepções pedagógicas (artigo 206, II e III), procurando dessa maneira formar os cidadãos brasileiros.

\section{Educação e pessoas com deficiência}

Vistas as linhas gerais acima apontadas, notamos que o direito à educação deve ser prestado a todas as pessoas, de forma igualitária, sendo seus objetivos regidos pelo princípio da dignidade humana.

Somente por essa afirmação, já poderíamos deduzir que as pessoas com deficiência têm o mesmo direito que as outras pessoas de ingressarem e permanecerem na escola, para sua adequada formação como cidadãos, seu pleno desenvolvimento como seres humanos, bem como para sua capacitação para o mercado de trabalho.

A Constituição, entretanto, não se contentou em fixar os princípios genéricos da educação, a serem interpretados, como visto, de acordo com os princípios da dignidade humana e da igualdade, mas cuidou de 
expressamente garantir às pessoas com deficiência o pleno acesso à educação, nos estabelecimentos da rede regular de ensino, determinando o oferecimento de atendimento educacional especializado, conforme disposição do artigo 208, III, da Lei Maior. É dizer, devem ser utilizados os instrumentos necessários, ensinados preferencialmente na rede regular de ensino, com vistas a possibilitar às pessoas com deficiência o adequado aprendizado do conteúdo constante do currículo escolar de cada nível de ensino.

Em outras palavras, a Constituição, como forma de garantir a isonomia no acesso à educação, determinou que seja oferecido atendimento educacional especializado, sendo que tal atendimento deverá ocorrer, preferencialmente na rede regular de ensino.

Deve-se ter muita cautela na interpretação da norma trazida pelo artigo 208, III, da Constituição, coadunando-a com o todo do Texto Constitucional, de forma a não permitir, ao invés da consagração da isonomia, sua frontal ofensa. Não se deve entender que as crianças com deficiência devem "preferencialmente" frequentar as escolas da rede regular de ensino; isso não está em questão: a Constituição determinou, expressamente, no artigo 206, I, que todos, pessoas com deficiência ou não, devem ter condições igualitárias de acesso e permanência nas escolas; essa a única interpretação que se coaduna com os princípios da isonomia e da dignidade humana, vetores de interpretação de nossa Constituição.

O que se deve extrair do artigo 208, III, da Constituição, é que o atendimento educacional especializado deve ser oferecido, é um direito das pessoas com deficiência (o que, em última análise, já seria uma decorrência do princípio da igualdade), e esse atendimento especializado deve, preferencialmente, ser ofertado na rede regular de ensino.

Atendimento educacional especializado não se constitui em um nível de ensino, não substitui o conteúdo curricular da educação básica (formada pela educação infantil, pelo ensino fundamental e pelo ensino médio) ou da educação superior, que são os níveis escolares, previstos no artigo 21 da Lei de Diretrizes e Bases da Educação Nacional (Lei no 9.394/1996). Trata-se o atendimento educacional especializado de um instrumental destinado a propiciar que as pessoas com deficiência possam ter condições de aprenderem o conteúdo curricular dos diversos 
níveis de ensino, ou seja, é um conjunto de procedimentos, metodologias, ou mesmo equipamentos, cujo objetivo é possibilitar o adequado acesso das pessoas com deficiência à educação.

Tal atendimento especializado deve ser oferecido de forma complementar ou suplementar ao ensino, deve permear todos os seus níveis, eliminando as barreiras existentes para que as pessoas com deficiência possam adequadamente aprender o conteúdo curricular de cada nível de ensino, em igualdade de oportunidades com os demais estudantes.

A Lei de Diretrizes e Bases da Educação Nacional, em seu artigo 58, com a redação que lhe foi dada pela Lei no $12.796 / 2013$, aponta a educação especial como modalidade de educação escolar, a ser oferecida preferencialmente na rede regular de ensino, para educandos com deficiência, transtornos globais do desenvolvimento e altas habilidades ou superdotação, assegurando seu início já durante a educação infantil ( $3^{\circ}$ ). Note-se que o $\S 2^{\circ}$ do referido artigo 58 da Lei de Diretrizes e Bases da Educação Nacional somente autoriza que o atendimento educacional especializado seja oferecido em classes, escolas ou serviços especializados quando, em função das condições específicas dos alunos, não for possível a sua integração nas classes comuns do ensino regular; trata-se, assim, de medida excepcional, que somente deve ser adotada em casos de impossibilidade concreta de integração em função das condições do aluno, cujo bem-estar deve ser preservado. Ainda assim, devemos observar que a autorização legal, assim como a constitucional, restringe-se ao oferecimento do atendimento educacional especializado, e não ao currículo regular, fora da rede regular de ensino, quando a situação concreta assim o exigir.

A própria Lei de Diretrizes e Bases da Educação Nacional, em seu artigo 59, aponta alguns instrumentos que compõem o atendimento educacional especializado, como currículos, métodos técnicas, recursos educativos e organização específicos (I), terminalidade específica para alguns casos (II), professores especializados para atendimento educacional especializado (III).

Também a Lei no 7.853/1989, em seu artigo 2º̣, parágrafo único, I, “a”, aponta a necessidade de inclusão, no sistema educacional, da educação especial, como modalidade educativa que abranja a educação infantil, 
o ensino fundamental, o ensino médio, o ensino supletivo, bem como a habilitação e a reabilitação profissionais.

O Decreto $n^{\circ}$ 7.611/2011, que dispõe sobre a educação especial, define o atendimento educacional especializado como um conjunto de atividades, recursos de acessibilidade e pedagógicos, organizados institucional e continuamente, destinado à eliminação de barreiras que obstruam o processo de escolarização de estudantes com deficiência, transtornos globais do desenvolvimento e altas habilidades ou superdotação. Tal Decreto expressamente fixa como objetivos do atendimento educacional especializado a garantia da transversalidade das ações de educação especial no ensino regular, determinando seu oferecimento em todas as etapas e níveis de ensino ${ }^{2}$.

Temos, assim, que a Constituição Federal determina, em seu artigo 208, III, o oferecimento de atendimento educacional especializado, como forma de garantia ao direito à educação das pessoas com deficiência, em todos os níveis de ensino, atendimento especializado este que, preferencialmente, deve ser oferecido na rede regular de ensino.

Trata-se de medida que prestigia a igualdade, estabelecendo tratamento diferenciado para aqueles que estão em situações diferentes, com vistas a que todos tenham as mesmas oportunidades de acesso à educação, propiciando, ainda, a inclusão, prestigiando outro valor caro à nossa Constituição, a dignidade humana, evitando a segregação das pessoas com deficiência no ambiente escolar.

0 direito à educação das pessoas com deficiência também é constitucionalmente assegurado pelas disposições trazidas no artigo 24 da Convenção Sobre os Direitos das Pessoas com Deficiência da ONU, que foi recebida no ordenamento jurídico brasileiro como norma com equivalência de emenda à Constituição, na forma do artigo 5oㅗ §3oㅡㄹ da Lei Maior, já que internalizada mediante aprovação das duas Casas do Congresso Nacional em dois turnos de votação, por três quintos dos votos dos seus respectivos membros.

0 referido artigo 24 da Convenção, norma com equivalência constitucional, repita-se, aponta expressamente que o Estado deve garantir o direito à educação sem discriminação e com base na igualdade de oportunidades, assegurando sistema educacional inclusivo em todos os níveis. 
Determina, ainda, que as pessoas com deficiência não serão excluídas do sistema educacional geral sob alegação de deficiência, e que as crianças com deficiência não serão excluídas do ensino primário gratuito e compulsório ou do ensino secundário sob alegação de deficiência.

Como formas de garantia de acesso das pessoas com deficiência à educação, a Convenção determina que o Estado deverá assegurar a efetiva participação dessas pessoas no sistema de ensino e na vida em comunidade, adotando medidas apropriadas, como a facilitação do aprendizado do braile e outros métodos de comunicação alternativa, da linguagem de sinais, bem como a contratação e capacitação de profissionais, inclusive professores com deficiência, para atuarem em todos os níveis de ensino.

Determina a Convenção, ainda, no mesmo artigo 24 (item 2, "c"), que, para garantir o acesso das pessoas com deficiência aos estabelecimentos de ensino deverão ser providenciadas adaptações razoáveis, de acordo com as necessidades individuais. Trata-se da garantia da acessibilidade na escola, que deverá, na medida do possível, observar as necessidades individuais do aluno para que este tenha acesso adequado à educação; as pessoas com deficiência devem poder fisicamente ingressar e permanecer na escola para que possam aprender, de forma inclusiva, convivendo com os demais estudantes.

A adaptação razoável também vem definida na Convenção da ONU, como sendo as modificações e os ajustes necessários que não venham a acarretar ônus desproporcional ou indevido, quando requeridos em cada caso, de forma a assegurar que possam as pessoas com deficiência gozar ou exercer, em igualdade de oportunidades com as demais pessoas, todos os seus direitos e liberdades fundamentais (artigo 2).

Note-se que o "ônus desproporcional ou indevido" não pode ser interpretado como uma válvula de escape para que o Estado ou o particular deixem de cumprir com sua obrigação de acessibilidade, ou seja, não se pode, sob a singela argumentação de que uma determinada adaptação implique em ônus excessivo, deixar de promover a acessibilidade. A questão não pode ser verificada unicamente com base em critérios econômicos, mas deve levar em conta os bens jurídicos que a Constituição pretende proteger, implicando em uma necessária ponderação. Tendo em vista os bens jurídicos envolvidos no caso da adaptação de uma escola, 
quais sejam, a educação, a igualdade, a dignidade humana, a inclusão, em uma interpretação sistemática das normas constitucionais, o critério econômico tem reduzida drasticamente sua importância.

Ademais, não se pode alegar que houve alguma surpresa com a obrigação de implementação da acessibilidade, já que, desde 1988, com a promulgação da Constituição (artigos 227, §2 e 244), já há o dever de construir prédios públicos ou de uso público, como o caso das escolas, observando-se as diretrizes de acessibilidade, bem como foi fixado o dever de adaptação dos prédios existentes.

Não pode o estabelecimento de ensino, assim, recusar-se, por qualquer motivo, a realizar a matrícula da pessoa com deficiência, sendo sua obrigação promover as adaptações físicas necessárias para acolhê-la, bem como ofertar o atendimento educacional especializado, possibilitando à pessoa com deficiência a possibilidade de aprender todo o conteúdo curricular do nível de ensino que está cursando. Não existe "cota de inclusão", ou qualquer outra limitação à matrícula da pessoa com deficiência na escola. Não se pode exigir da família a contratação de profissional para o acompanhamento da criança, sendo obrigação da escola oferecer os meios para a inclusão da criança com deficiência no ambiente escolar.

Recentemente, foi editada a Lei no 13.146/2015, a Lei Brasileira de Inclusão da Pessoa com Deficiência (Estatuto da Pessoa com Deficiência). Tal lei dedica um capítulo inteiro ao direito à educação das pessoas com deficiência (Capítulo IV, do Título II), dispondo, em seu artigo 27, que a educação é direito da pessoa com deficiência, devendo ser assegurados sistema educacional inclusivo em todos os níveis e aprendizado ao longo de toda a vida. Referida Lei, em seu artigo 28 , $§ 1^{\circ}$, expressamente determina que o sistema educacional inclusivo em todos os níveis e modalidades, assim como diversos outros mecanismos de efetivação da inclusão, são aplicáveis às instituições privadas, vedada a cobrança de valores adicionais de qualquer natureza em mensalidades, anuidades e matrículas.

0 que demonstramos com essa breve delineação do direito à educação, sob a perspectiva das pessoas com deficiência, na forma como ele vem posto nos nossos sistemas constitucional e infraconstitucional, é que a educação é direito de todos, constituindo-se em dever do Estado, que presta tal serviço público essencial de forma direta ou mediante autoriza- 
ção para que os particulares o prestem. Tal direito tem sua configuração pelas balizas constitucionais da igualdade, da dignidade humana e da inclusão, sendo de rigor que as pessoas com deficiência, por sua peculiar condição, tenham estabelecido um tratamento diferenciado, de forma a equiparar suas oportunidades de desenvolvimento pleno da personalidade, de formação para o exercício da cidadania e de preparação para o mercado de trabalho às oportunidades oferecidas às demais pessoas.

Esse tratamento diferenciado implica no oferecimento de um atendimento educacional especializado, que deverá ser realizado preferencialmente na rede regular de ensino (o que inclui escolas públicas e particulares), bem como na necessária adaptação para que as pessoas com deficiência possam adequadamente frequentarem os estabelecimentos de ensino, da mesma forma como os frequentam as demais pessoas.

Tendo em vista que a Constituição é norma jurídica, dotada de obrigatoriedade e efetividade, não se pode sonegar o acesso à educação às pessoas com deficiência, argumentando a falta de preparo para receber um aluno com deficiência, já que a Lei Maior determina, expressamente, o dever de oferecimento de atendimento educacional especializado e de adaptação razoável, não cabendo ao Estado, ou ao particular por aquele autorizado, deixar de efetivar a matrícula de um aluno com deficiência. Os estabelecimentos de ensino, públicos ou privados, têm o dever de adaptarem-se e de oferecerem o atendimento educacional especializado para que as pessoas com deficiência tenham o acesso a todo o conteúdo curricular do respectivo nível de ensino, da mesma forma que as pessoas sem deficiência, salvo raríssimas situações excepcionais legalmente estabelecidas, que devem ser verificadas diante do caso concreto, com efetiva demonstração da impossibilidade de inclusão, sempre levando em consideração o bem-estar da pessoa envolvida ${ }^{3}$.

\section{0 direito à inclusão e a realidade da exclusão}

Recentemente, o jornal Folha de S. Paulo noticiou uma realidade que infelizmente é muito comum em nosso país: a exclusão das crianças com deficiência das escolas da rede regular de ensino (BILENKY, 2015). 
A reportagem do jornal procurou dezoito escolas da capital de São Paulo pretendendo realizar a matrícula de uma criança com deficiência, uma criança de seis anos de idade com síndrome de Down, tendo obtido resposta positiva, sem restrições, como manda a Constituição Federal, em apenas sete delas. Mais da metade das escolas procuradas desencorajou, impôs restrições indevidas, recusou ou simplesmente não respondeu ao pedido de matrícula da criança com deficiência. A notícia não é nova.

Dentre os motivos alegados pelas escolas para não efetivar a matrícula da criança com deficiência intelectual, a reportagem elenca: confessada falta de preparo dos funcionários para receber uma criança "diferente"; preenchimento da quota de pessoas com deficiência (sabemos que não há a referida cota), necessidade de contratação de um "assistente" por conta dos pais. As negativas tiveram os mais variados motivos, como visto, todos, evidentemente, inaceitáveis e ilegais.

0 fato reflete não apenas um problema localizado na capital paulista, mas uma tendência que se encontra presente nas escolas brasileiras. A efetividade dos dispositivos constitucionais, portanto, carece de esforço para se realizar.

A ausência de acolhimento das pessoas com deficiência nas escolas da rede regular de ensino, em flagrante desrespeito ao Texto Constitucional, tem como efeito algo muito além da sonegação do direito à educação, e implica na perpetuação da exclusão desse grupo vulnerável.

Deixar de receber as crianças com deficiência, além de obviamente danoso a elas, é tão ou mais danoso às crianças sem deficiência, que ficam privadas da convivência com a diferença, que têm ceifada a oportunidade de aprenderem a desenvolver seus sensos de tolerância e solidariedade. A convivência de pessoas com e sem deficiência desde a mais tenra idade, desde os bancos escolares, certamente é o mais forte instrumento de efetiva inclusão do grupo das pessoas com deficiência na sociedade (ARAUJO, 2014; WERNECK, 2009). As pessoas com deficiência são simplesmente parte da diversidade humana, não havendo qualquer razão para que sejam segregadas do convívio social pleno.

Muitas vezes as pessoas deixam de ajudar pessoas com deficiência unicamente por não saber como fazê-lo, por um constrangimento gera- 
do justamente pela falta de convivência e de entendimento do próximo. Como não estão habituadas ao convívio com as pessoas com deficiência, não sabem como agir diante de alguém nessa condição.

O efeito da segregação do grupo vulnerável é gerar mais segregação. Pela falta de convivência com as pessoas com deficiência, arquitetos e engenheiros, mesmo conscientes da existência de normas de acessibilidade, não se lembram das pessoas com deficiência na hora de projetarem os prédios e equipamentos urbanos; o legislador não considera essas pessoas quando da elaboração das políticas públicas e da legislação; o administrador público esquece de incluir o grupo vulnerável quando executa as leis e presta os serviços públicos; o Poder Judiciário não tem a necessária proximidade da questão para decidir de acordo com a proteção que o sistema normativo brasileiro oferece às pessoas com deficiência. Não é por simples descaso ou por despreparo técnico que as pessoas com deficiência ficam deixadas de lado ou não são adequadamente consideradas pelos profissionais das mais diversas áreas, mas uma boa explicação talvez resida na falta de vivência da situação, na falta de proximidade com as pessoas com deficiência, na falta de efetivo entendimento dos problemas enfrentados por aquelas pessoas.

A convivência deve começar no ambiente escolar. É absolutamente saudável que as crianças convivam com a diferença, percebendo desde cedo que as pessoas são diferentes umas das outras, com suas qualidades e dificuldades próprias. Formando pessoas mais inclusivas abrimos caminho para a eliminação da exclusão.

Recusar a matrícula de uma criança com síndrome de Down, assim, é atitude que não está em nenhuma hipótese ou sob nenhuma justificativa agasalhada pelo ordenamento constitucional brasileiro, constituindo-se em grave afronta ao direito a educação e à inclusão, violando direito fundamental da pessoa com deficiência e de sua família, sendo de rigor que o Direito interfira para evitar o dano ou, quando impossível, repará-lo. Trata-se de recusa à efetivação do próprio direito à educação, cabendo, dessa forma, a reparação do dano pelos meios disponíveis no ordenamento jurídico brasileiro para a tutela dos direitos individuais e difusos ofendidos. 


\section{Os danos causados pela recusa da matrícula escolar em razão da deficiência}

Primeiramente, devemos considerar que o próprio direito à educação, constitucionalmente assegurado a todas as pessoas, é violado com a recusa da matrícula escolar da pessoa com deficiência. De fato, tal atitude das direções das escolas provoca um dano difuso, uma afronta ao direito fundamental à educação, e não apenas um dano à pessoa com deficiência que teve sua matrícula recusada. Tal dano ao direito à educação, por si só, já é passível de reparação pelo nosso ordenamento jurídico.

Por outro lado, da recusa da matrícula escolar em razão da deficiência, podem surgir danos materiais e morais à pessoa com deficiência que teve sua matrícula recusada, violações ao patrimônio jurídico da pessoa com deficiência diretamente envolvida no caso concreto, danos estes também reparáveis pela via judicial. Vejamos.

\subsection{0 dano difuso aos direitos à educação e à inclusão}

Como indicamos acima, a recusa da escola em proceder à matrícula de uma pessoa com deficiência, em razão da deficiência, é atitude que, inicialmente, provoca dano ao próprio direito à educação, ao direito difuso constitucionalmente garantido, violando, ainda, o dever de inclusão trazido pela nossa Lei Maior.

0 direito à educação das pessoas com deficiência, assim como o direito à inclusão, poderão ser tutelados de forma coletiva, mediante a atuação do Ministério Público, da Defensoria Pública, das pessoas políticas, ou de entidade que tenha dentre seus objetivos institucionais a defesa do direito das pessoas com deficiência ou do direito à educação.

Os direitos à educação e à inclusão são direitos difusos, já que são direitos transindividuais, de natureza indivisível, de que são titulares pessoas indeterminadas ou indetermináveis, ligadas por circunstâncias de fato.

0 direito à educação e à inclusão são direitos fundamentais a todos garantidos, são direitos cujos titulares são indeterminados e indetermi- 
náveis, cabendo, assim, no caso de sua violação, a reparação mediante os mecanismos legais destinados à proteção dos direitos difusos.

A recusa de matrícula em razão da deficiência, dessa forma, atenta contra direitos de toda a sociedade, contra direitos dos quais todos somos titulares.

\subsection{Os danos individuais causados pela recusa da matrícula escolar da pessoa com deficiência}

Além da violação aos direitos à educação e à inclusão propriamente ditos, ou seja, além da violação aos direitos difusos, a atitude adotada pelas escolas ao recusarem a matrícula das pessoas com deficiência provoca danos ao patrimônio jurídico das pessoas com deficiência que tiveram sua matrícula recusada, é dizer, provoca um dano individual, mensurável, à pessoa com deficiência, dano este que também poderá ser objeto de pedido de reparação.

A pessoa com deficiência que teve a matrícula recusada pela escola é atingida em seu patrimônio e em sua dignidade, cabendo, dessa forma, indenização por danos morais e materiais.

Devemos apontar, assim, que tanto podem, e devem, ser adotadas medidas para a preservação efetiva do direito à educação, garantindo a matrícula do aluno, como podem ser adotadas medidas que pretendam ver reparado algum dano que não se conseguiu evitar, seja ele material ou moral, individual ou coletivo, inclusive como forma de evitar-se novas violações a tal direito.

\section{Dano material}

Ocorrido o dano, ou seja, não tendo sido possível evitar o prejuízo à pessoa com deficiência, é cabível sua reparação. Todos os danos patrimonialmente mensuráveis decorrentes da conduta ilegal da escola em recusar a matrícula da pessoa com deficiência são indenizáveis.

A recusa da escola pode gerar, por exemplo, prejuízo patrimonial decorrente de gastos com locomoção, busca de outro estabelecimento, 
psicólogos, assessoramento jurídico, enfim gastos financeiros das mais variadas ordens.

Nosso ordenamento jurídico prevê que aquele que em decorrência de ato ilícito provoque prejuízo a outrem tem o dever de indenizar, de reparar o dano e, dessa forma, sendo a recusa de matrícula em razão da deficiência um ato que não é admitido pelo nosso Direito, como demonstramos, é absolutamente cabível a indenização pelo dano material.

\section{Dano moral}

Ocorre que não é apenas em seu patrimônio material que a pessoa com deficiência, e suas famílias, são lesadas com a recusa da matrícula escolar em razão da deficiência. Há também o dano moral, que, possivelmente, supera em muito o dano patrimonial.

0 constrangimento experimentado pela pessoa com deficiência que teve negado seu direito à matrícula, a dor decorrente da exclusão provocada por tal ato, bem como o prejuízo causado à sua formação são indenizáveis, já que o dano moral é tutelado pela Constituição Federal, na forma do disposto em seu artigo $5^{\circ}, \mathrm{X}$.

Não se pode admitir que passe indene ato que provoque efeitos tão deletérios à personalidade de uma pessoa como a recusa do estabelecimento de ensino de recebê-la, unicamente por sua condição de pessoa com deficiência. A deficiência é parte da diversidade humana, sendo que nosso ordenamento constitucional determina como objetivo republicano a construção de uma sociedade livre, justa e solidária (artigo 3ํㅡ, I) e a promoção do bem de todos, sem quaisquer discriminações (artigo 3oㅡㄴ. IV).

A recusa da matrícula pela escola em razão da deficiência não pode ser entendida com um acontecimento corriqueiro, inerente à vida em sociedade, mas deve ser interpretado como ato que impõe um dano muito severo à personalidade da pessoa com deficiência vitimada, que lhe afronta em sua dignidade, sendo cabível, dessa forma, a reparação moral.

Tanto o dano material, efetivamente comprovado, como o dano moral, que deverá ser mensurado pelo Poder Judiciário, são indenizáveis, sendo de rigor a condenação do infrator, inclusive para que se obtenha o efeito de evitar novas violações ao direito juridicamente tutelado, 
motivo pelo qual a fixação da indenização deverá levar em consideração suas consequências econômicas para o condenado; não se pode admitir uma condenação que para o condenado soe irrisória, estimulando-o a realizar novas violações ao direito fundamental protegido, mas também não se pode condenar o infrator de forma a arruiná-lo financeiramente, impedindo que continue o exercício de suas atividades, agora de acordo com o determinado pelo sistema jurídico.

Para conseguir a indenização pelo dano material e pelo dano moral deverá a pessoa com deficiência ingressar com ação perante o Poder Judiciário, demonstrando a extensão do dano sofrido e sua relação com o ato ilegal praticado.

Dessa forma, poderá a pessoa com deficiência preservar seu direito à educação pela via administrativa, mediante petição ao Poder Público ou ao Ministério Público, ou pela via judicial, utilizando-se dos meios processuais postos à sua disposição pelo nosso ordenamento jurídico, notadamente o mandado de segurança. Violado seu direito, poderá pedir a reparação do dano experimentado, material ou moral, acessando o Poder Judiciário, sem prejuízo de continuar buscando a efetivação do seu direito à educação, que não poderá ser sonegado, e nunca poderá se limitar a uma condenação em perdas e danos.

\section{Mecanismos para efetivação do direito à educação}

Verificados os danos causados pelas escolas com a recusa da matrícula em razão da deficiência, danos estes difusos e individuais, materiais e morais, de rigor que procuremos em nosso ordenamento jurídico instrumentos que permitam evitar que os danos se instalem, ou, caso não seja possível evita-los, maneiras de promover a sua reparação.

\subsection{Mecanismos extrajudiciais}

Primeiramente, devemos nos perguntar se é possível que a família da criança impeça a efetivação do dano, ou seja, se é possível conseguir com que a escola seja obrigada a efetivar a matrícula da criança com 
deficiência e resguardar de forma efetiva seu direito à educação. Evidentemente a resposta é positiva; nosso ordenamento jurídico garante o direito à educação e nos dá instrumentos para sua salvaguarda. Vejamos.

O serviço público de educação será prestado pelo Estado ou por particulares autorizados e fiscalizados pelo Poder Público, na forma trazida pelo artigo 209, da Constituição Federal.

Nesse sentido, ainda na via administrativa, poderá a família (ou pessoa com deficiência, quando maior e capaz), peticionar diretamente ao Poder Público competente (Municipal, Estadual, Distrital ou Federal, conforme o estabelecimento ou nível de ensino para o qual teve a matrícula recusada), junto à Delegacia de Ensino ou órgão equivalente, requerendo que seu direito à educação seja efetivado e seja determinada a matrícula. $\mathrm{O}$ direito de petição ao Poder Público contra ilegalidade ou abuso de poder é expressamente garantido na Constituição Federal, independentemente do pagamento de taxas, conforme artigo 5으, XXXIV, "a", da Lei Maior.

O Poder Público tem o dever de agir para a efetivação do direito do administrado, e deverá notificar a escola para que dê cumprimento ao disposto na Constituição, realizando a matrícula pretendida. Caso isso aconteça, o problema estará resolvido, sem a intervenção do Poder Judiciário, de uma forma bastante célere.

Poderá a pessoa com deficiência, ou sua família, ainda, pedir a intervenção do Ministério Público para a resolução da questão, já que tal Entidade é constitucionalmente competente para zelar pelo efetivo respeito dos Poderes Públicos e dos serviços de relevância pública aos direitos assegurados pela Constituição, promovendo as medidas necessárias a sua garantia, bem como para a defesa de interesses difusos e coletivos, como o direito à educação (Constituição Federal, artigo 129, II e III).

Ademais, em se tratando da defesa de direito de incapaz ou de pessoa com deficiência, o Ministério Público tem atribuição legal para fazê-lo inclusive judicialmente, o que legitima tal Órgão a agir.

O Ministério público, provocado pela pessoa com deficiência ou sua família, poderá oficiar ao Poder Público competente ou mesmo ao estabelecimento de ensino requerendo que seja efetivada a matrícula, ou solicitando maiores informações, que poderão inclusive subsidiar medi- 
das judiciais a serem adotadas. A questão também poderia ser resolvida, assim, com uma petição ao Ministério Público.

\subsection{Mecanismos judiciais}

No entanto, pode a pessoa com deficiência não ter conseguido a preservação de seu direito à educação pela via administrativa, ou mesmo pode simplesmente preferir o caminho judicial, por entendê-lo mais efetivo e seguro. Nesse caso poderá utilizar-se dos instrumentos processuais colocados à sua disposição pela Constituição e pelas Leis, lembrando que o acesso ao Poder Judiciário no caso de lesão, ou ameaça de lesão a direito, é a todos garantido, nos termos do artigo 5ํㅡ, XXV, da Constituição.

Também o dano difuso ao direito à educação poderá ser reparado pela via judicial, efetivando as disposições da Constituição Federal, mediante instrumentos próprios previstos em nosso Direito.

\section{Tutela judicial individual do direito à educação}

Como já mencionado, a prestação de serviço de educação, ainda quando realizada pelo particular, constitui-se em prestação de serviço público essencial e, dessa forma, os atos praticados que violem direito líquido e certo das pessoas com deficiência são passíveis de impugnações pela via do Mandado de Segurança, trazida pelo artigo 5으, LXIX e LXX, da Constituição.

Cabe o Mandado de Segurança quando for praticado por autoridade pública ou por agente de pessoa jurídica no exercício de atribuições do Poder Público (como o caso do diretor de uma escola particular, por exemplo) ato ilegal ou com abuso de poder, violando direito líquido e certo não amparável por habeas corpus ou habeas data.

No caso da recusa de matrícula, parece-nos evidente a violação a direito líquido e certo, garantido inclusive constitucionalmente, de acesso igualitário à educação, bem como de oferecimento de atendimento educacional especializado, sendo perfeitamente cabível a impugnação pela via do mandado de segurança. A família, utilizando-se de um advogado, ou da Defensoria Pública, impetrará uma ação na Justiça competente 
(poderá ser a Justiça estadual ou federal, de acordo com o estabelecimento de ensino ou com o nível de ensino no qual se pretende realizar a matrícula), pedindo ao Poder Judiciário que determine a realização da matrícula da pessoa com deficiência naquele estabelecimento, em decisão com caráter mandamental.

Poderá ser requerido, em casos de perigo na demora, com possibilidade de perecimento do direito (como por exemplo o início do período letivo com prejuízo ao aluno que deixar de acompanhar o começo das atividades), a concessão de liminar, para que desde logo seja garantido o direito à matrícula.

Trata-se o Mandado de Segurança de meio de efetivação do próprio direito, que evita o prejuízo ao direito à educação e corrige a ilegalidade praticada.

Não se pode descartar, ainda, o ingresso com ação de conhecimento pelo rito ordinário, visando o reconhecimento do direito à matrícula da pessoa com deficiência, pedindo liminarmente a efetivação do ato até que a ação tenha seu resultado final. Nesse tipo de ação é até possível cumular o pedido de matrícula com pedido por indenização por eventual dano material ou moral experimentado pela pessoa com deficiência e sua família.

\section{Tutela judicial coletiva do direito à educação}

Como acabamos de ver, a recusa da matrícula de uma criança com deficiência é ato que atenta contra o direito fundamental à educação, e não encontra qualquer agasalho ou justificativa em nosso sistema constitucional. A reparação do dano individualmente causado àquele que teve sua matrícula recusada em razão da deficiência não basta, não repara toda a violação à ordem jurídica ocorrida.

Mister se faz que também o direito à educação, bem como o direito à inclusão, sejam recompostos, em sua perspectiva difusa. A reparação individual é apenas parte da reparação devida, sendo de rigor que seja também apurado e indenizado o dano difuso.

O Ministério Público, a Defensoria Pública, as pessoas políticas, ou entidades que tenham dentre seus objetivos institucionais a defesa do 
direito das pessoas com deficiência ou do direito à educação poderão agir em juízo para a efetivação e a reparação dos direitos violados.

Quando uma escola ou o Poder Público deixarem de matricular um aluno em razão da deficiência, violando, assim, além do direito individual desse aluno os direitos difusos à educação e à inclusão, poderão aqueles legitimados trazidos pelo artigo 5o da Lei no 7.347/1985 intentar a ação civil pública, com vistas a obter a reparação do dano ocorrido.

Outrossim, é de se notar que, nos termos do artigo $3^{\circ}$ da Lei $\mathrm{n}^{0}$ $7.853 / 1989$, poderão ser propostas ações civis públicas para a proteção de interesses difusos e coletivos das pessoas com deficiência pelo Ministério Público, pela União, pelos Estados, pelos Municípios, pelo Distrito Federal, por associação constituída há mais de um ano, nos termos da lei civil, autarquia, empresa pública, fundação ou sociedade de economia mista que inclua, dentre suas finalidades, a proteção das pessoas com deficiência.

O Ministério Público deverá intervir em todas as ações, públicas, coletivas ou individuais, em que se discutam interesses relacionados à deficiência das pessoas (artigo 5oㅡ, da Lei no 7.853/1989). Note-se, outrossim, que a intervenção do Ministério Público não se dará em todas as ações em que figurem como parte as pessoas com deficiência, mas apenas naquelas em que o objeto da ação esteja relacionado com a deficiência, exatamente como parece ser o caso da recusa de matrícula em razão da deficiência.

A ação civil pública poderá ser intentada inclusive de forma cautelar, para se evitar o dano ao direito das pessoas com deficiência (artigo $4^{\text {o }}$ da Lei no 7.347/1985).

Percebendo, por exemplo, que uma escola reiteradamente vem recusando a matrícula de pessoas com deficiência, seja por provocação de alguém, ou mesmo por notícia veiculada na imprensa, poderá o Ministério Público, após recolher elementos que comprovem minimamente a recusa, intentar a ação civil pública, cujo objeto seja o cumprimento de obrigação de fazer ou não fazer, ou mesmo a condenação em dinheiro daquela escola. Poderá pleitear, assim, que a escola se abstenha de recusar a matrícula de pessoas com deficiência, se o motivo da recusa for exclusivamente a deficiência, bem como que pague indenização a um 
fundo de reparação de direitos difusos pela prática até então reiterada de recusar a matrícula dessas pessoas.

Poderá o Ministério Público, também, utilizar-se do inquérito civil

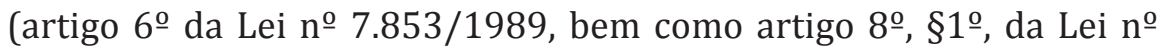
$7.347 / 1985)$, para apurar a violação dos direitos das pessoas com deficiência, instrumento que poderá resultar na celebração de um termo de ajustamento de conduta, em que o violador do direito compromete-se a cumprir os ditames da lei, ou mesmo na propositura da ação civil pública.

Dessa forma, temos que a lei prevê meios de tutela coletiva para que se evite o dano ao direito à educação das pessoas com deficiência, bem como para que, uma vez violado esse direito, haja a justa reparação, ou, se impossível, a indenização.

\section{Considerações finais}

Por todo o exposto, podemos afirmar que o direito à educação das pessoas com deficiência é constitucionalmente garantido, e, segundo a conformação que a Lei Maior lhe dá, tal direito impõe a educação inclusiva, fazendo com que as pessoas com deficiência convivam no ambiente escolar com as demais pessoas, lhes sendo garantido atendimento educacional especializado para que possam adequadamente aprender o conteúdo curricular de seu respectivo nível de ensino.

Segundo uma interpretação sistemática da Constituição, que privilegia valores como a igualdade, a dignidade humana e a inclusão, não se pode admitir a segregação das pessoas com deficiência no ambiente escolar, cabendo ao Poder Público, e aos particulares que prestam os serviços de educação mediante autorização estatal, propiciar os meios e condições para o acolhimento das pessoas com deficiência no ambiente escolar.

Não podem as escolas recusarem, sob qualquer pretexto, a realização da matrícula de pessoas com deficiência, sendo sua obrigação promover a adaptação razoável de seus estabelecimentos, bem como oferecer o atendimento educacional especializado. Não existe qualquer "cota de inclusão" ou outro subterfúgio que desobrigue as escolas de matricularem qualquer criança com deficiência. 
Violado tal direito, as pessoas com deficiência, e suas famílias, podem procurar sua efetivação tanto pela via administrativa, utilizando-se do direito de petição que a Constituição coloca à disposição de todos, ou mesmo da possibilidade de petição ao Ministério Público, como pela via judicial, utilizando-se de todos os meios que o Direito brasileiro coloca à disposição para a salvaguarda dos direitos subjetivos.

A tutela do direito à educação das pessoas com deficiência poderá ser realizada tanto de forma individual como coletiva, seja para a efetivação do direito como para a reparação por sua violação, assim, como para a indenização pelos danos materiais e morais que advenham da inconstitucional recusa de acesso ao sistema educacional.

\section{Notas}

1 Dados do Censo 2010 do Instituto Brasileiro de Geografia e Estatística - IBGE, disponíveis em: <ftp://ftp.ibge.gov.br/Censos/Censo_Demografico_2010/Caracteristicas_Gerais_Religiao_Deficiencia/tab1_3.pdf>.

2 Também em nível infralegal, a Resolução CNE-CEB no 2, de 11 de setembro de 2001, do Conselho Nacional de Educação, estabelece as diretrizes nacionais para a Educação Especial na Educação Básica. 0 artigo 2o de tal Resolução, inclusive, expressamente afirma que os Sistemas de ensino têm o dever de matricular todos os alunos, "cabendo às escolas organizar-se para o atendimento aos educandos com necessidades educacionais especiais, assegurando as condições necessárias para uma educação de qualidade para todos", fixando, ainda, no seu artigo 7ํㅜ , que o atendimento dos alunos com deficiência deve ser realizado em classes comuns do ensino regular, em qualquer etapa ou modalidade da educação básica.

3 Importante ressaltar recente decisão liminar do Supremo Tribunal Federal, em sede de ação direita de inconstitucionalidade (ADI no 5357), movida pela Confederação Nacional dos Estabelecimentos de Ensino, que pretende a declaração de inconstitucionalidade dos artigos 28 , $\S 1^{\circ}$ e 30, caput, do Estatuto da Pessoa com Deficiência, que, em síntese, obrigam as escolas privadas a oferecerem atendimento educacional especializado às pessoas com deficiência, sem nenhum custo adicional, sob o argumento de que seriam estabelecidas medidas de alto custo para as escolas privadas, podendo chegar a inviabilizar suas atividades. 0 Ministro Relator, Edson Fachin, indeferiu o pleito de liminar (que pretendia ver suspensa a eficácia dos dispositivos legais impugnados), sob o fundamento, em síntese, de que a igualdade não apenas impõe a previsão normativa de acesso igualitário aos bens jurídicos, mas necessita de que sejam também previstas medidas que efetivamente possibilitem tal acesso e sua efetivação concreta. Reconhecendo a Convenção Sobre os Direitos das Pessoas com Deficiência da ONU como parte integrante da Constituição Federal, apontou que é dever do Estado facilitar às pessoas com deficiência seu acesso pleno e sua igual participação no sistema de ensino e na vida em comunidade, o que é perfeitamente compatível com a determinação do Estatuto da Pessoa com Deficiência de que as escolas privadas promovam as adaptações necessárias à inclusão das pessoas com deficiência, sem repassarem seus custos às mensalidades, anuidades e matrículas. Apesar de ser um juízo provisório, o posicionamento do despacho que indeferiu a liminar já revela a preocupação com a aplicação da Convenção sobre os Direitos da Pessoa com Deficiência da ONU e do texto Constitucional, quando fala em educação, democracia e direito de todos. (Decisão monocrática de 18/11/2015, publicada no DJE no 234 , de 19/11/2015). 


\section{Referências}

ARAUJO, Luiz Alberto David. A proteção constitucional das pessoas com deficiência. 4. ed. Brasília: Corde, 2011.

ARAUJO, Luiz Alberto David. Barrados: pessoas com deficiência sem acessibilidade: como, o que e de quem cobrar. Petrópolis: KBR, 2011.

ARAUJO, Luiz Alberto David. Um breve quadro da proteção constitucional das pessoas com deficiência no Brasil. Legislação basta? Uma tentativa de diagnóstico. Revista Inclusiones, v. 1, n. 3, p. 19-30, jul./set., 2014. Disponível em: http://www.revistainclusiones.cl/volumen-1-nba3/oficial-articulo-dr.-luizalberto-david-araujo.pdf. Acesso em: 20 mai. 2015.

BANDEIRA DE MELLO, Celso Antônio. 0 Conteúdo jurídico do princípio da igualdade. 3. ed. 20a tiragem. São Paulo: Malheiros Editores, 2011.

BILENKY, Thais. Matrícula de criança com Down divide colégios particulares de São Paulo. Folha de S. Paulo, São Paulo. 15 mar. 2015. Disponível em: http:// www1.folha.uol.com. br/educacao/2015/03/1602926-matricula-de-criancacom-down-divide-colegios-particulares-de-sp.shtml. Acesso em: 18 abr. 2015.

DIAS, Joelson; FERREIRA, Laíssa da Costa; GUGEL, Maria Aparecida; COSTA FILHO, Waldir Macieira da (Coord.). Novos comentários à Convenção sobre os direitos das pessoas com deficiência. 3. ed. Brasília: Secretaria Nacional de Promoção dos Direitos da Pessoa com Deficiência - SNPD, 2014.

FÁVERO, Eugênia Augusta Gonzaga. Direitos das pessoas com deficiência: garantia de igualdade na diversidade. 2. ed. Rio de Janeiro: WVA, 2007.

MAZZILLI. Hugo Nigro. A defesa dos interesses difusos em juízo: meio ambiente, consumidor, patrimônio cultural, patrimônio público e outros interesses. 28. ed. São Paulo: Saraiva, 2015.

MAZZILLI. Hugo Nigro. 0 ministério público e a pessoa com deficiência. GUGEL, Maria Aparecida; COSTA FILHO, Waldir Macieira da; RIBEIRO, Lauro Luiz Gomes (Org.). Deficiência no Brasil: uma abordagem integral dos direitos das pessoas com deficiência. Florianópolis: Obra Jurídica, 2007. 
NUNES JÚNIOR, Vidal Serrano; SCIORILLI, Marcelo. Mandado de segurança: ação civil pública, ação popular, habeas data, mandado de injunção. 3. ed. São Paulo: Verbatim, 2014.

PONTES, Patrícia Albino Galvão. Educação Inclusiva. In: GUGEL, Maria Aparecida; COSTA FILHO, Waldir Macieira da; RIBEIRO, Lauro Luiz Gomes (Org.). Deficiência no Brasil: uma abordagem integral dos direitos das pessoas com deficiência. Florianópolis: Obra Jurídica, 2007.

WERNECK, Claudia. Ninguém mais vai ser bonzinho na sociedade inclusiva. 3. ed. Rio de Janeiro: WVA, 2009.

Recebido em: 3-12-2015

Aprovado em: 3-2-2016

\section{Luiz Alberto David Araujo}

Doutor em Direito Constitucional pela Pontifícia Universidade Católica de São Paulo (PUC/SP); mestre em Direito pela Pontifícia Universidade Católica de São Paulo (PUC/SP); bacharel em Direito pela Universidade de São Paulo (USP); Procurador Regional da República aposentado.

Avenida Iraí 393, cj 72 Indianópolis, 04082001, São Paulo, SP, Brasil. Pontifícia Universidade Católica de São Paulo, Faculdade de Direito.

E-mail: lada10@terra.com.br

\section{Maurício Maia}

Doutorando e mestre em Direito Constitucional pela Pontifícia Universidade Católica de São Paulo (PUC/SP); professor Assistente do Curso de Especialização em Direito Administrativo da (PUC/SP - COGEAE); membro efetivo da Comissão de Direito Administrativo da OAB/SP; procurador Federal.

Advocacia-Geral da União, Procuradoria Regional Federal da $3^{\text {a }}$ Região. Rua da Consolação, 1875, 11ํo andar, Consolação, 01301100, São Paulo, SP,Brasil.

E-mail: mauriciomaia@uol.com.b 
